\title{
BASIC LEARNING OF FORM
}

\author{
Magda Mària i Serrano (D), Sílvia Musquera Felip (D), Luis Beriain Sanzol \\ Universitat Politècnica de Catalunya (Spain) \\ magda.maria@upc.edu,silvia@3carme33.com,luis.beriain@upc.edu
}

Received December 2017

Accepted March 2018

\section{Abstract}

"Form is 'what', Design is 'bow"' (Kahn, 1960). Learning about the formal universe and the wide range of possibilities it offers should be one of the purposes of the early subjects in architectural studies. This article aims to explain the contents of a first course of architectural design and demonstrate how, using a methodology based on precise theoretical-practical tools and an active pedagogical dynamic, results are obtained that, on average, are very satisfactory. It shows that in twelve weeks' time, students have acquired the tools they need to approach any design problem from its form.

Keywords - Form, Add form, Transform, Architectural design, Project, Learning methodology.

\section{Introduction}

Students entering from Baccalaureate have generally had an education based on grammatical, mathematical or musical languages. For this reason, one of the objectives that early courses in architecture must address is teaching form languages in order to achieve their gradual mastery, so that they can be applied on all scales and in all facets of architectural design. Following the examples of pioneering schools in the application of active instructional systems to the teaching of design, such as the methods used by Vkhutemas -Moscow, 1920-1930(Khan-Magomedov, 1990), Bauhaus-Weimar, 1919-Berlin 1933-(Droste, 1993), and Hochschule für Gestaltung -Ulm, 1953-1968- (Krampen \& Hörmann, 2003), this early immersion in the grammar of form is articulated through very specific contents linked to a very concrete methodology. In the case of the courses in question, which correspond to the first year of Architectural Design, this instruction is implemented in two parts. The first, focused on form, is implemented in the course Bases for Design I. The second, which complements the first, continues in the course Bases for Design II. Its correlative contents employ the learning about form as the basis for the development of architectural space in its many different facets.

Specifically prioritizing the subject of forms in an early architectural design course is in line with, among other things, the basic definitions some architects give to the architectural design process and architecture itself. Adolf Loos describes it as "an art of space and form" (Loos, 1898/1993). Le Corbusier also stresses its formal attributes by specifying that "architecture is the wise, correct, magnificent game of volumes under light" (Le Corbusier, 1923). Louis I. Kahn states that "form, as the harmony of systems, is the generatrix of the project" (Kahn, 1962).

On the other hand, the structured knowledge of the formal language offers the advantage of mastering a universal vocabulary and grammar that are present in many aspects of life, and therefore, applicable not only to architecture, but to a wide range of disciplines. At the beginning of the 20th century, Theodore Cook (Cook, 1914) and D'Arcy Thomson (Thomson, 1917) already brought to light the common areas that exist between the forms of nature, art and architecture. Other architects, such as Frank Lloyd Wright (Dezzi-Bardeschi, 1977), Le 
Corbusier (Ozentfant \& Jeanneret, 1921) and Louis I. Kahn (Kahn, 1962; 1969) also backed this confirmation. This transversality is crucial during these years of basic learning, because it makes it possible to recognize the presence of forms and space in the many different manifestations of reality and, along with it, acquire the capacity to resolve an important spectrum of topics in design and construction that are obviously implied in architecture.

\section{Form and design}

"Form is 'what'. Design is 'bow"' (Kahn, 1960).

The Diccionario de la Lengua Española defines the word Proyecto as the set of plans and documents that provide the necessary data required to construct an object, an instrument or a building according to a set program (www.rae.es).

In English, the term design would be the equivalent of Proyecto. In a more generic sense, design defines the formalization process that is followed in the development of a new object, topic or activity. Design is the path taken between the problem and the solution, having to resolve the established propositions with the appropriate forms. Form is, according to this definition, the solution to the problem and the focus of the project. Specifically, it is that which must respond to all the inputs dictated by the architectural requirements.

In German, there are different words that etymologically refer to Projects: Gestaltung, which means formation, and Formgebung, which can be translated as the act of giving shape to something.

Based on these concepts that define Project as design in its most intrinsic meaning, the contents of this initial beginner's course are proposed. In other words, it is conceived based on the design definition as a process through which we manage to resolve a proposition through form. Providing a proper formal solution to the problem presented, investigating the possibilities for a particular use through its configuration is the challenge of any design, regardless of whether it is in architecture or any other discipline. For this reason, we believe that establishing these bases well from the very beginning of a student's studies is fundamental.

Form as the articulating force is studied, in the first year, based on three of its different facets (Tatarkiewicz, 1975/2002), specifically those that contribute to comprehension and the construction of reality:

Form as the figure that determines the exterior of matter;

Form as the compositional structure of similar elements;

Form as the volumetric creator of space.

\section{Methodology}

"In architecture, like in poetry, different creative phases do not occur; there is no distinction between matter and form, thought and act, author and executor" (Zevi, 1960).

The contents of the three stages in this formal immersion are based on strategies that enable students to journey from thought to deed and from deed to thought. Form is not being, rather making.

Form is born from making or creating through a process of design (Argan, 1951/1983). On this journey, the devised forms really begin to take shape, in an exercise that requires economy, precision and the absence of waste on both a mental and a material level. In general, we tend to neglect practical aspects in favor of theoretical ones, and we are not aware that thinking and making depend on each other in such a way that one can only be understood based on the other (Aicher, 2001). For this reason, this teaching and learning process combines theory (concepts and ideas) through periodic master lectures, with practice (actions and activities) in the form of exercises carried out primarily in the workshops. 
Dialog also comes into play in this methodology. Parallel to making and thinking, dynamic groups are held to comment on works, in order to motivate student participation, the sharing of problems and solutions, and the articulation of conclusions that make it possible to advance in the learning process. Along the lines of David Kolb's Experimental Learning, after a preliminary personal work phase, the necessary reflections are made on the different experiences and the results obtained. Within this dialectic, students are urged to publicly articulate the reasons that lead them to make some formal decisions and not others. Through these reflections, conclusions or generalizations are reached that refer to a set of broader circumstances than each student's specific experience. The conclusions obtained are used as a guide to direct the actions in future situations (Kolb \& Fry, 1975).

At the same time, in the group discussions, a comparison exercise is carried out, establishing analogies and differences among all the works presented, to stimulate the capacity for analysis and improve the project process.

As a result, the three stages of learning that are systematically implemented throughout each course session are:

The theoretical stage, where the design solution is established before being reached. In this stage, the most important thing is the contents of the lectures given by the teachers, which are aimed at both reflection on the topic in question and the analysis of examples and study cases directly linked to the exercise that will be performed in the workshop.

The practical stage, only through which can the design solution be specified, through a process of trial and error. In this stage, the most important thing is the work by the students, through their reflections, experiments, drawings and three-dimensional models carried out in the workshop and finished at home or in the studio over the course of a week. This stage is carried out in the workshop classroom, under the supervision of different professors.

The collaborative stage, where the design solution is revealed through the responses from different assignments completed by the students and discussed as a group. In this stage, both the students and the teachers play a primary role. The most significant works of the week are chosen, some of which are classified according to their formal proximity, and the students are invited to explain the different solutions and to participate in their commentary analysis. During this time, the students' arguments are explored, comments are given by the professors and questions are answered from the rest of the students.

The group discussion is held in the Design Studio Classroom, around tables arranged with displays of all the models presented. Diagrams, plans and photographs by the students are shown in digital format on a large screen. These are submitted beforehand through the "Atenea" digital platform, which provides support for teaching at UPC; this permits a closer look at the designs selected for discussion. The students give oral presentations on their projects and learn to be critical with their own work and that of their classmates by simultaneously comparing different answers to the same question.

The aim is to simultaneously carry out the three learning stages which, on the one hand, are autonomously established, but on the other hand, refer to one another and are interdependent. In them, abstract conceptualization and logical precision must coexist with practical experience, intuition and sensory perception (Aicher, 2001), and with dialog, collective presentations and collective reflection. It is only in this manner that a progressive approach is achieved to the complexity of design, without stylistic prejudices, understanding it as the desire to "give everything its own structural logic and its logical material, and thus its logical form" (Munari, 1968).

The sessions permit the students to take full advantage of the 5 hours and 30 minutes per week, using a flip teaching, where the focus is on the student, who is learning, reflecting and sharing his/her project process with the rest of the students. 

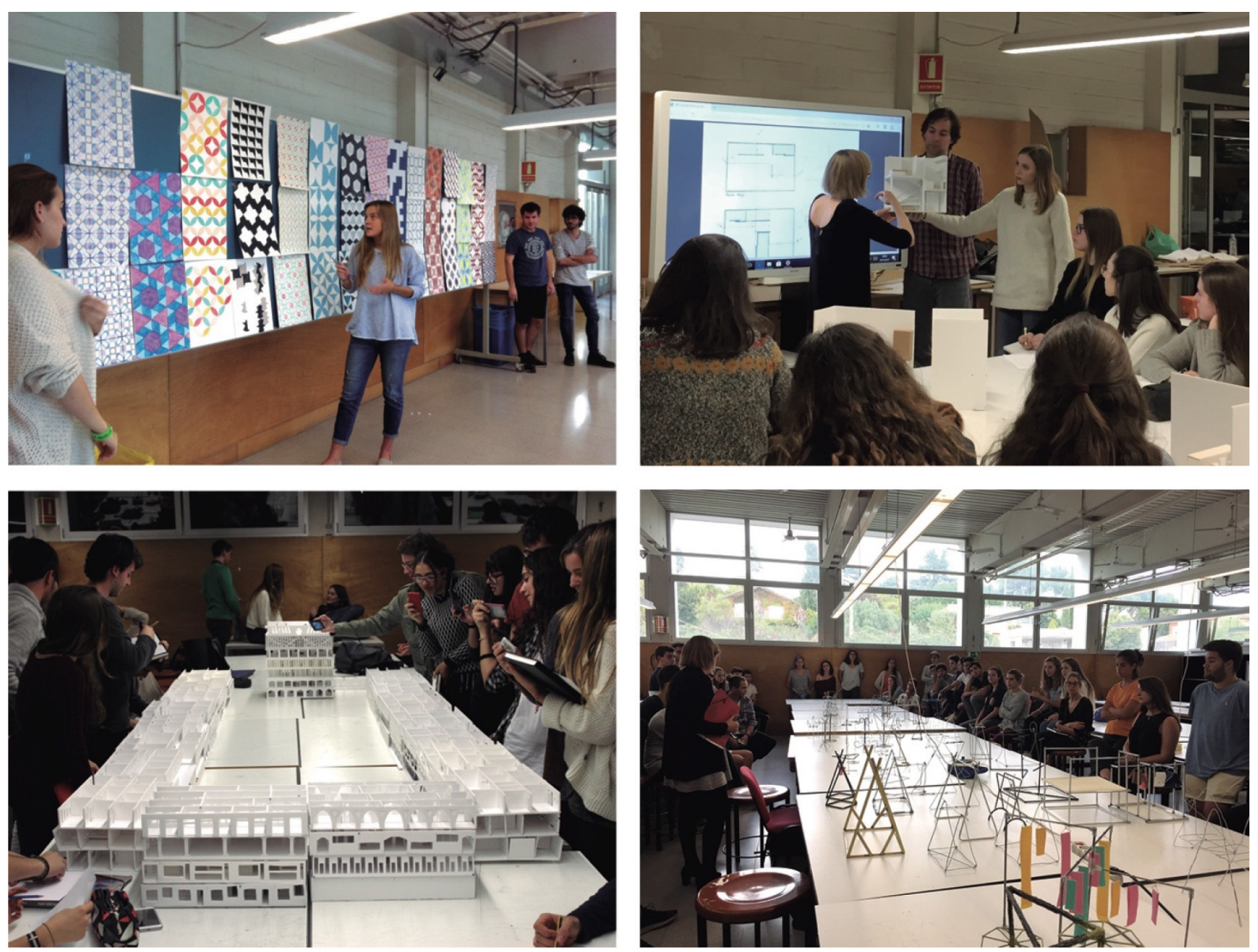

Figure 1. Photographs of the group in different collaborative sessions (2016)

During the course we organize a group visit to a sector in the city of Barcelona that, due to its characteristics, is directly related to the formal universe studied during the course. The students participate in a type of "treasure hunt," in which they must identify and draw a series of simple, complex or associated forms so that they can begin to practice observing the world around them from a different perspective, learning to interpret it and draw it in diagrams made in situ.
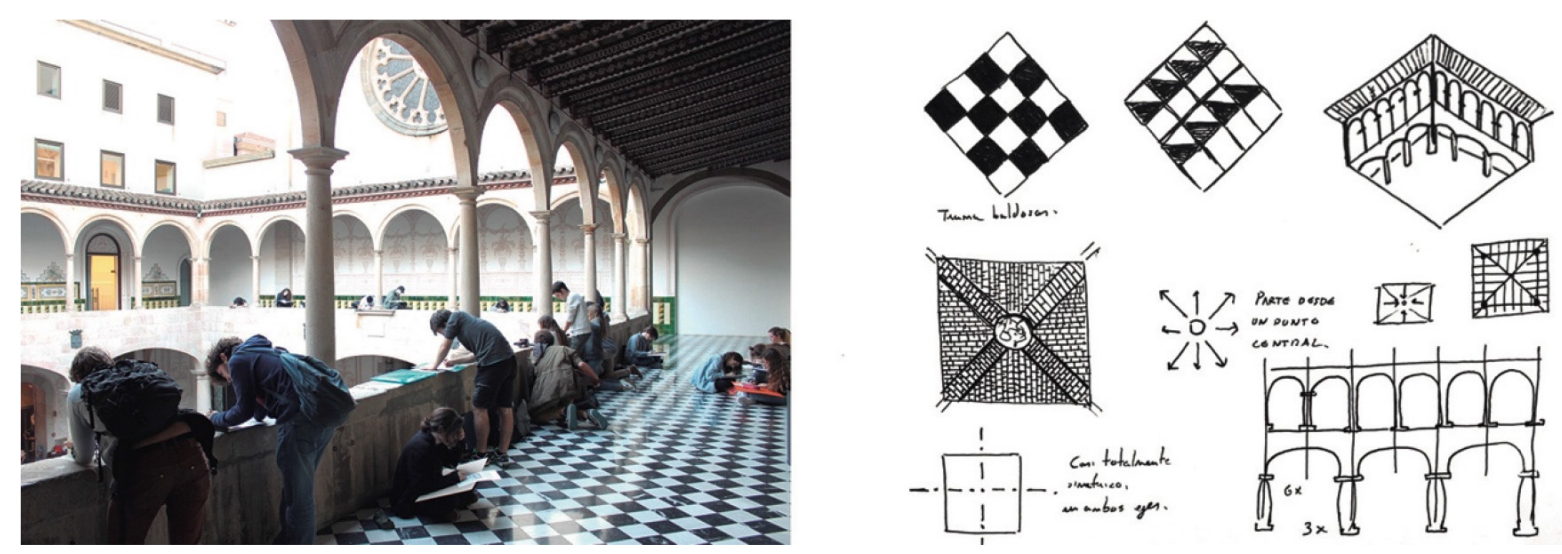

Figure 2. Photograph of the practical session outside the classroom. The students drawing the Pati Manning and the work of student Javier Guerrero (2016) 


\section{Instruments}

"I remember the adventure design when, inspired almost as in a dream, form, in order to be created, was forced to submit to the laws of order" (Kahn, 1962).

Instilling order in the design process means, among other things, having the right instruments to do so. There are essentially three instruments proposed as basic tools for learning:

The log consists of creating a record of what happens by keeping a diary. Like a navigator's logbook, which tells about the events of a sea crossing through texts, tables, numbers, sketches and photographs, the students keep an up-to-date work log, which they record in a notebook. In it, they write, calculate, draw, include materials, photographs or objects, paint, transfer references, pose questions and reflections. The intent is to reflect everything that happens in both the lectures and the work process, from start to finish. It makes it possible to see the different stages in the approach to the design of the forms and objects of each student. It is a valuable instrument that explains each of the learning processes, in which the hierarchy of events and anecdotes is equalized, because they all become valuable through their recording.

Drawing is essential to describing, but also to understanding. Drawing is not an auxiliary, complementary or subsidiary element: it is fundamental. In this first course, drawing is addressed, with an emphasis on drawing by hand. As Richard Sennet explains, the hand and the head maintain a close relationship, creating a dialog that evolves until it becomes a habit, which in turn, "establishes a rbythm between the solution and the discovery of problems" (Sennett, 2009).

A drawing always means a selection that highlights the most important elements and excludes those that are not as important. It is also a mental act aimed at one objective: the description of the object, and at the same time, the manifestation of the process used to approach it.
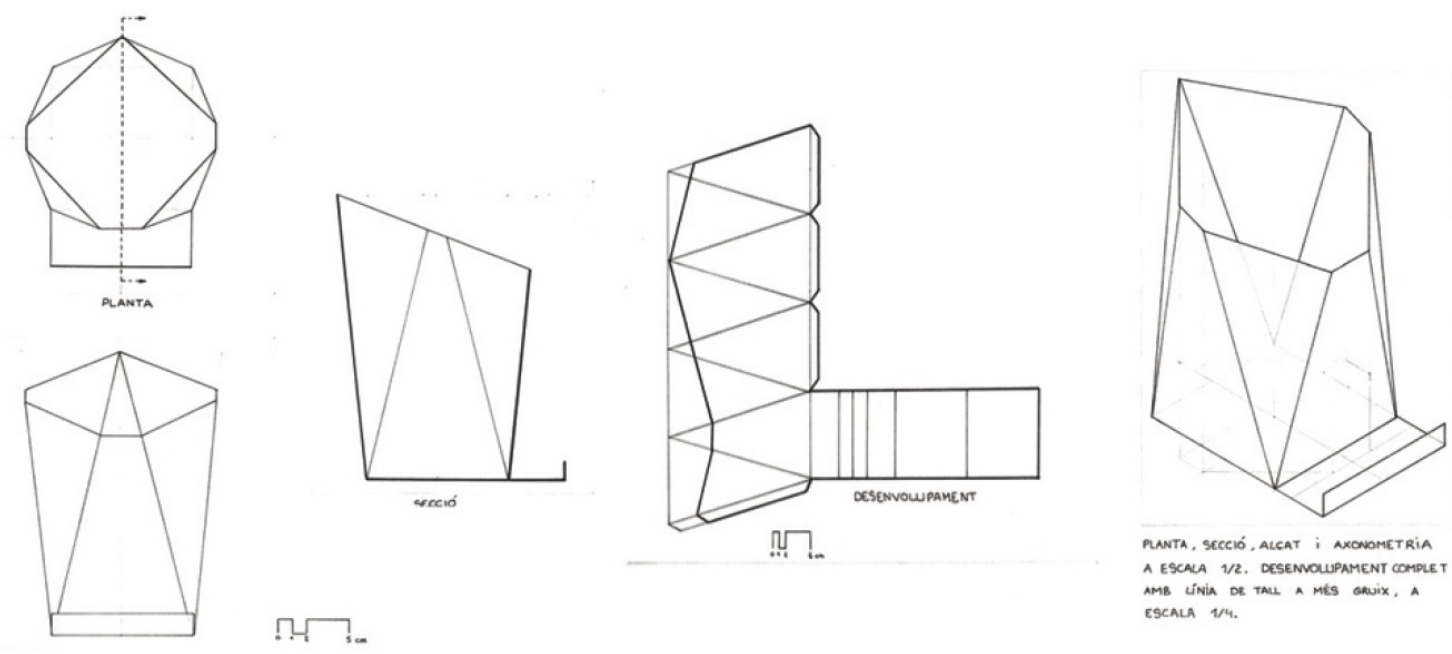

PANTA, SECCEÓ, ALCAT i NXONOMETRIA A ESCLNA 1/2. DESENOWUAMENT COMDLE, AMB LiNiA De

Figure 3. Drawing of the plans for the lamp (exercise 2) designed by student Eric Romeu (2016)

Construction is essential in order to check, using this experiential learning method, the effectiveness of the design. This course is one for craftsmen. Craftsmen, like producers, are trained in the workshop, creating and thinking at the same time. At the Bauhaus, there were no teachers and students, rather masters and apprentices who, like in a traditional workshop, made direct contact with the material in order to transform it (Argan, 1951/1983). Sennett recently lamented about how history has drawn false dividing lines between "practice and theory, technique and expression, craftsman and artist, producer and user; modern society suffers from this historical heritage" (Sennett, 2009).

In this course, we build what we think; we check whether our ideas are possible. Design must be developed in the realm of the possible so that in the future it can be turned into reality. For this reason, 
the students check for themselves the feasibility of their designs, building them on a real scale or as a model. In doing so, they see how the shaping of a proposal is taken from a generalization and is made productive.

The advantages are thus seen of using the most appropriate materials, the necessary thicknesses, the proper work time; the virtues are seen of giving maximum functions to a single object, coming up with simple solutions for joints or sound solutions for assembly mechanisms. Students are encouraged to provide maximum quality (functional, technical, perceptive and experimental) in all exercises.

By checking ideas through their construction, the intent is to implement the design without any preconceived stylistic ideas, basically following the nature of the formation of things, in order to obtain essential products with maximum economy of resources (Munari, 1968).
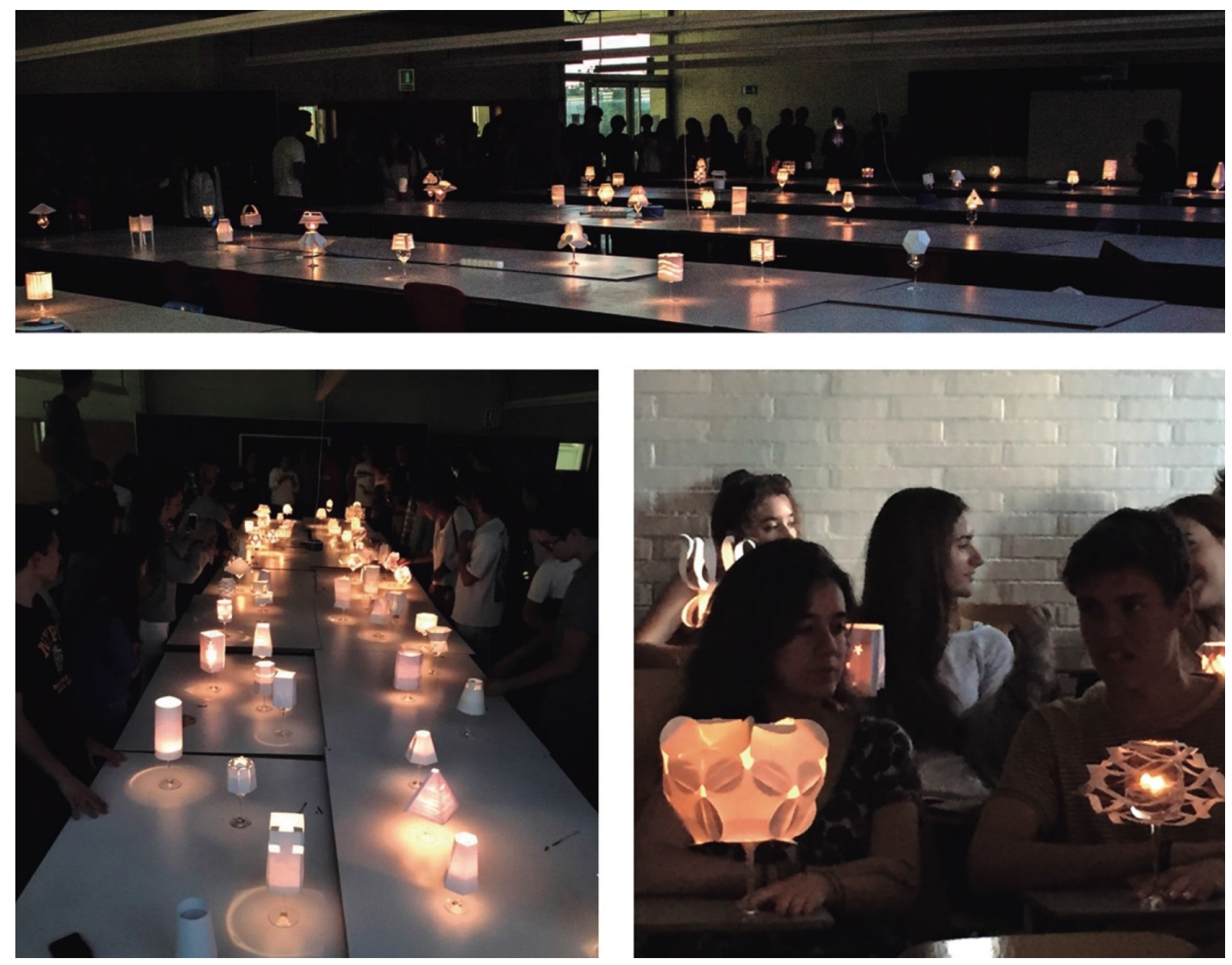

Figure 4. Photographs of lamps from exercise 2 in the workshop classroom (2016)

\section{Contents and Results}

The course contents are taught in three successive episodes that acquire greater complexity as the course advances.

The first episode, Form, studies the capacity of the basic forms to create different kind of objects; in the second, Shape, students work with the aggregation of basic forms with other similar or different and their potential to build connections and systems of growth; in the third, Transform, the versatility of the forms and aggregation systems is used to respond to functions and different requirements, checking their capacity for reformulation, optimization and adaptation. 


\subsection{Form}

Two lecture sessions are intended to introduce students to the contents that will be addressed throughout the course. The first lesson, Form and project, explains to the students the basic elements of an architectural design, while the second lesson, Geometric shapes on a plane and in space, analyzes the basic forms and their many different combinations applied to the creation of objects, works of art and architecture.

The students, based on these first sessions, complete two exercises that both use the same construction material: white poster board. The first exercise requires students to design and build a container on a real-life scale for their drawing material, using basic forms. The result is objects composed by the addition of volumes that meet different storage needs.
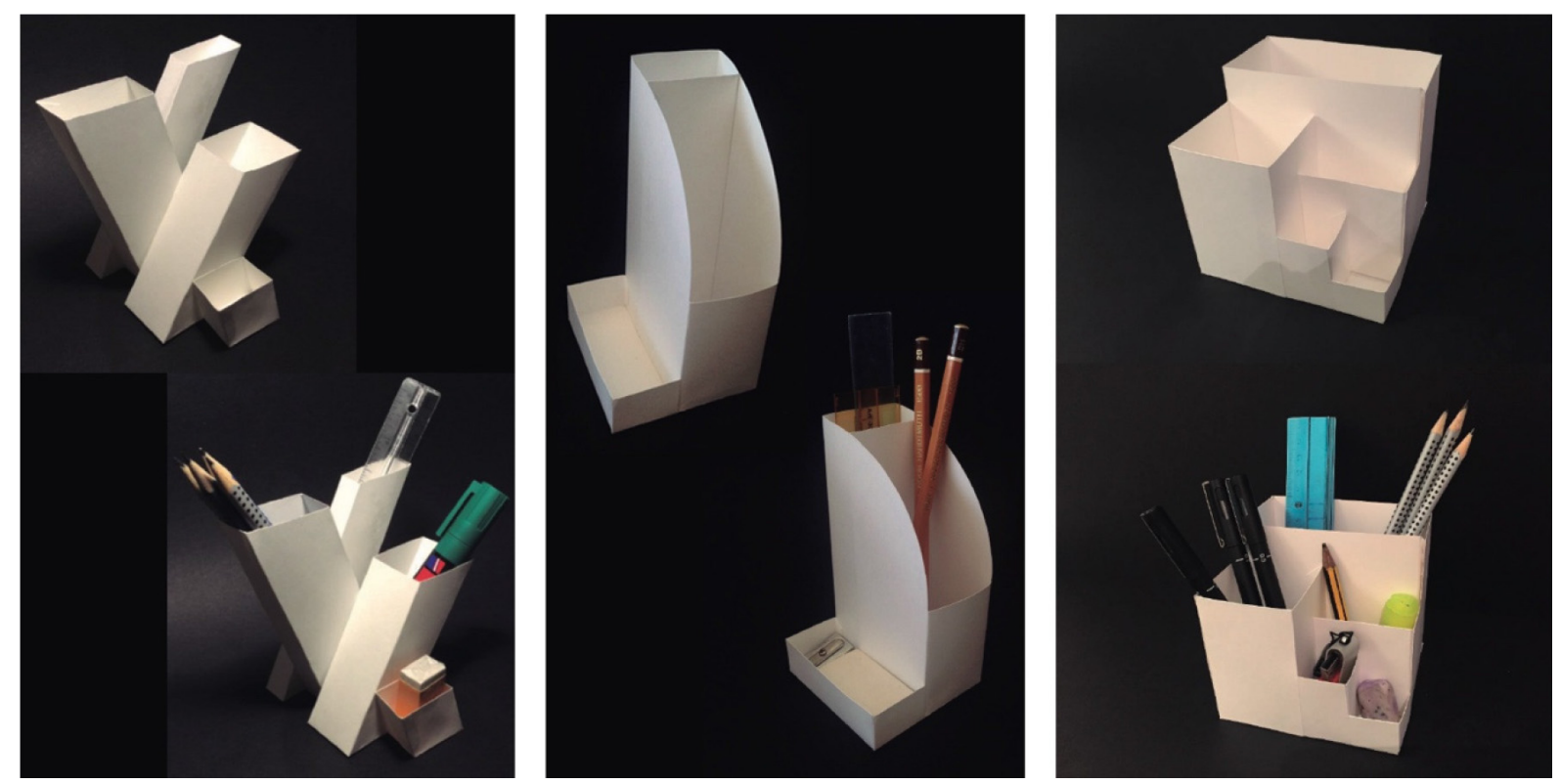

Figure 5. Photographs of models from exercise 1 (students D. Sellarès, L. Ginés and J. Beltrà, 2016)
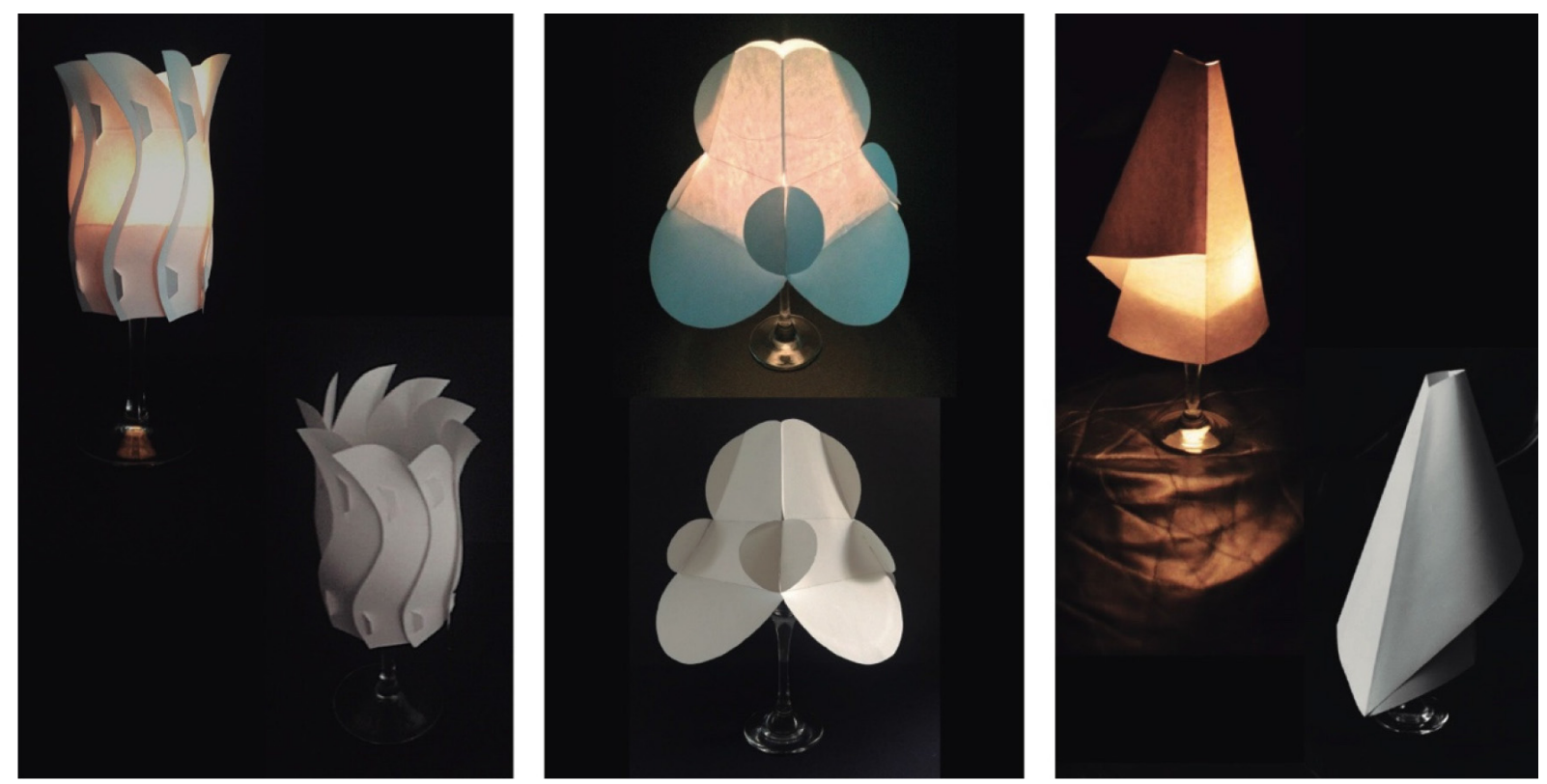

Figure 6. Photographs of models from exercise 2 (students B. Ribaudí, S. Gas and J. Vázquez, 2016)

In the second exercise, the students design and create a lamp from a glass, a piece of white poster board and a candle that must remain lit without burning the paper shade. Through the use of basic forms, the concepts of structure, volume and light emerge. In this exercise, both the instructions and the response increase the level of complexity required to solve the problem. 


\subsection{Shape}

At this stage, the students are introduced to the relations established between basic forms in order to create complex systems that can be applied to architecture, to resolve compositions on plane and in space.

In the Shape stage, four theoretical lectures are given. In the first, Forms and systems of growth, different systems are studied of grouping basic shapes on planes and in space, as well as the geometry of assembly that permits multiple combinations of geometric forms through translation, reflection, rotation or double reflection. The second lesson, Systems of growth and arcbitecture, focuses on the study of the basic three-dimensional elements applied to architecture, such as lattices, brise-soleil, grills or woven patterns, analyzing their assembly system, materials and, at the same time, their function as visual, solar and spatial filters. In the third, Forms, figures and rbythms, the different rhythms are studied that can be applied to both architectural elements and façade solutions: simple, complex, die-cut, altered and volumetric rhythms, and regulating meshes. In the fourth, Proportions and balance, proportions and regulating lines are analyzed as instruments to shape architecture.

All sessions are directly linked to the instructions for the proposed exercises. In them are numerous examples that help students answer the different questions presented.

In the third exercise, the students must design 1 to 4 tiles that can be combined to establish different patterns and to create a catalog of 3 of possible combinations. In the examples of the patterns created based on the geometric set of basic forms, the students show their capacity to combine forms and colors on a plane, putting into practice the knowledge they have acquired.
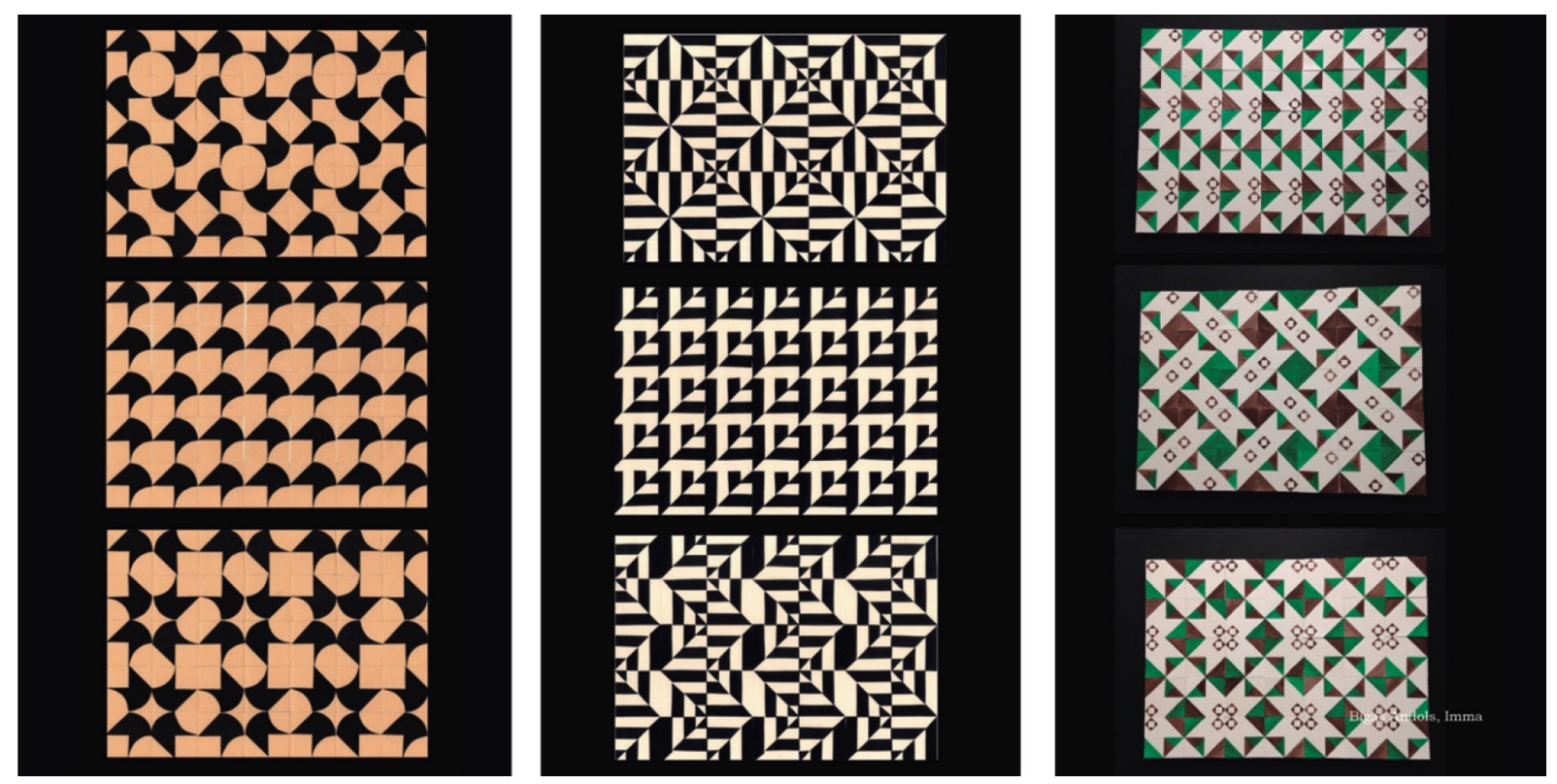

Figure 7. Photographs of the plans modeled in exercise 3 (students P. Quingles, S. Gas and I. Bigas, 2016)

In the fourth exercise, the proposal is the design and construction of different combinations of tiles within a space defined by different planes, applying the patterns projected in the design of coverings and pavements. The tile catalogs resulting from the previous conceptual exercise are applied in a space where the student establishes three-dimensional relationships between them, while at the same time introducing openings adapted to the geometry of the patterns. 

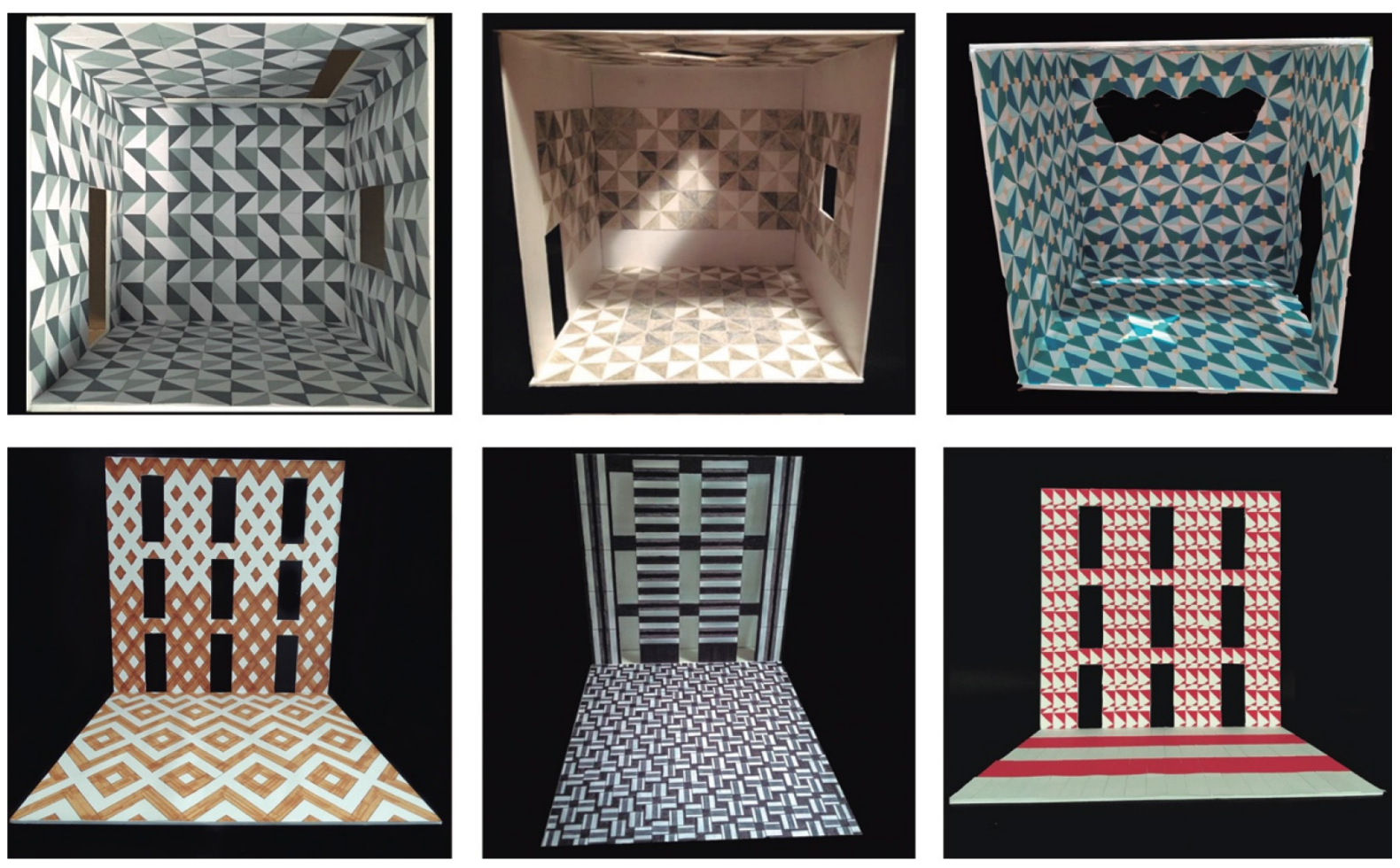

Figure 8. Photographs of the models from exercise 4 (students E. Romeu, R. Nogué and C. Borell, 2016; X. Pizà, A. Blejusca and L. Collado, 2017)

In the fifth exercise, a $30 \times 30 \mathrm{~cm}$ lattice is designed and created using a material selected by the student. This lends itself to a wide range of solutions resulting from the combination of a three-dimensional geometric system and materials that make it possible, such as wood, cardboard, metal, plastic, ceramic or paper.
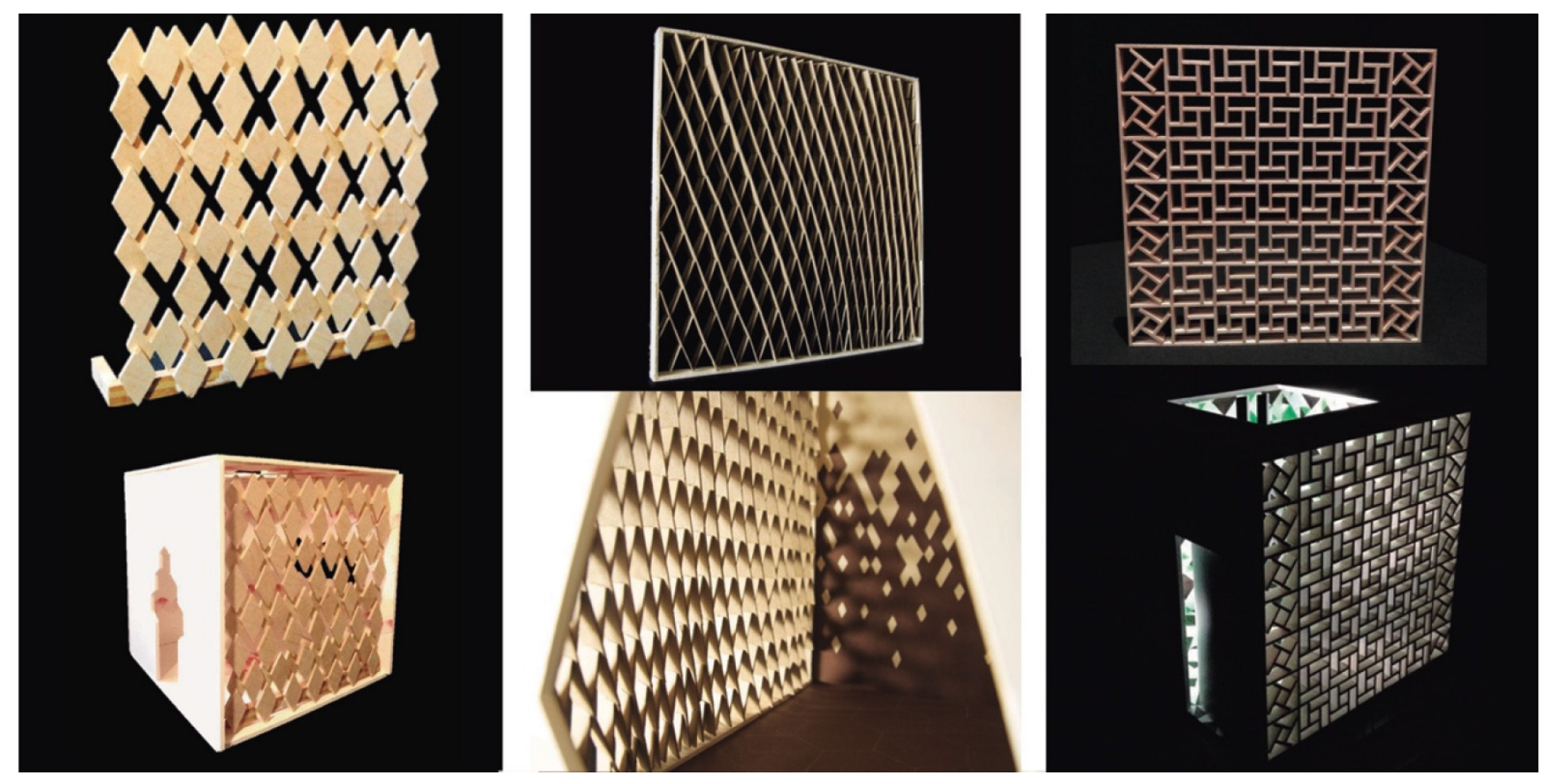

Figure 9. Photographs of the lattices from exercise 5 (students G. Ramón, P. Rodríguez and I. Bigas, 2016)

In the sixth and seventh exercises, a series of 5 parallel planes are designed and built, die cut with geometric forms, that are arranged on a rectangular surface, considering that the two outer planes are facades. The aim is to explore the rhythmic capacity of geometric spaces in different vertical planes and the relationships that are established between them to generate an interior space and façades. 

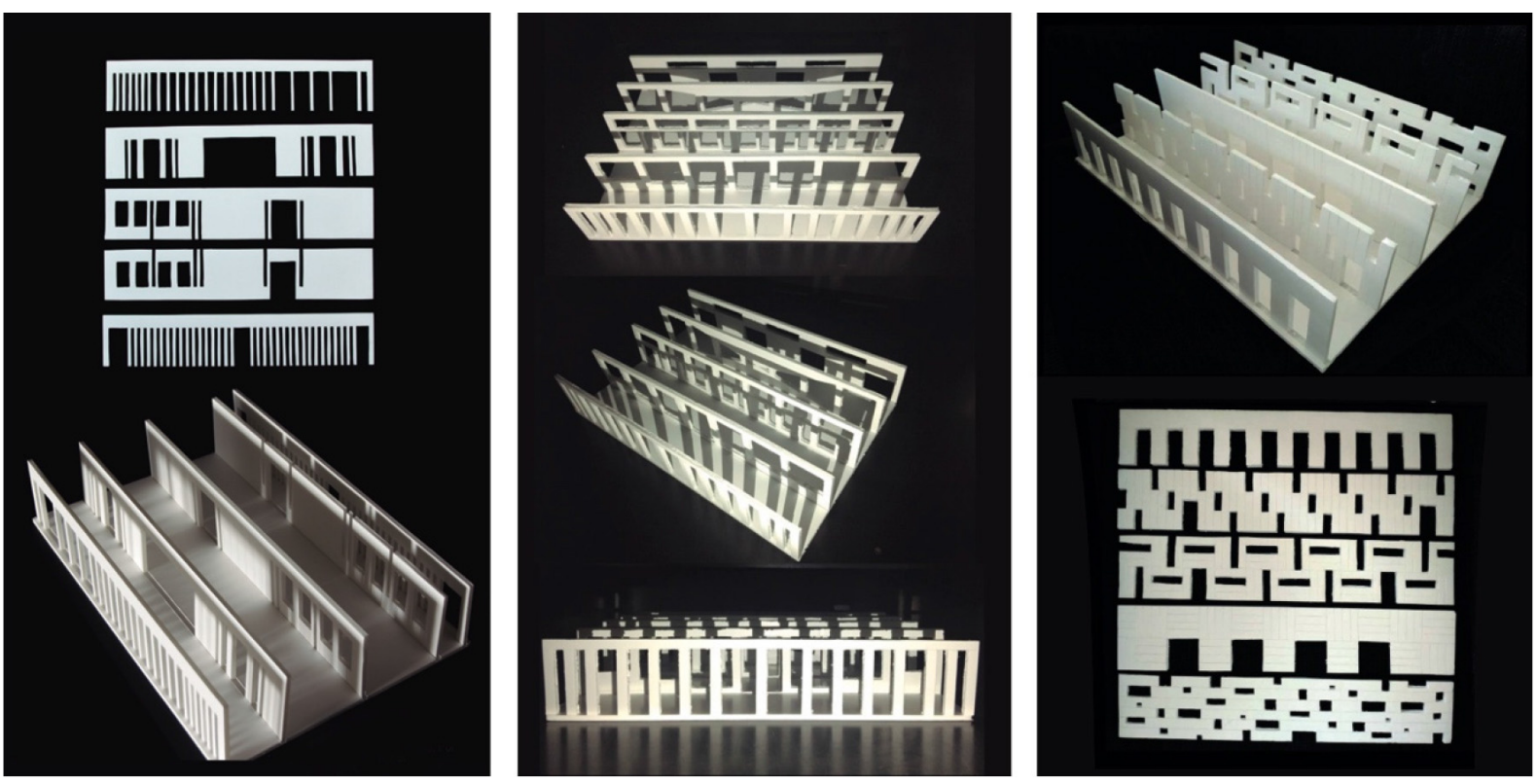

Figure 10. Photographs of architectural rhythms in exercise 6 (students P. Rodríguez, S. Gas and M. Comella, 2016)

Once each unit has been completed individually, the students proceed with the collective construction of a large model made from the aggregation of the models from all the students, creating an urban space (street or square) through the negotiated combination of the façade rhythms proposed by each student. The resulting model is drawn in perspective in the workshop from the different vantage points.
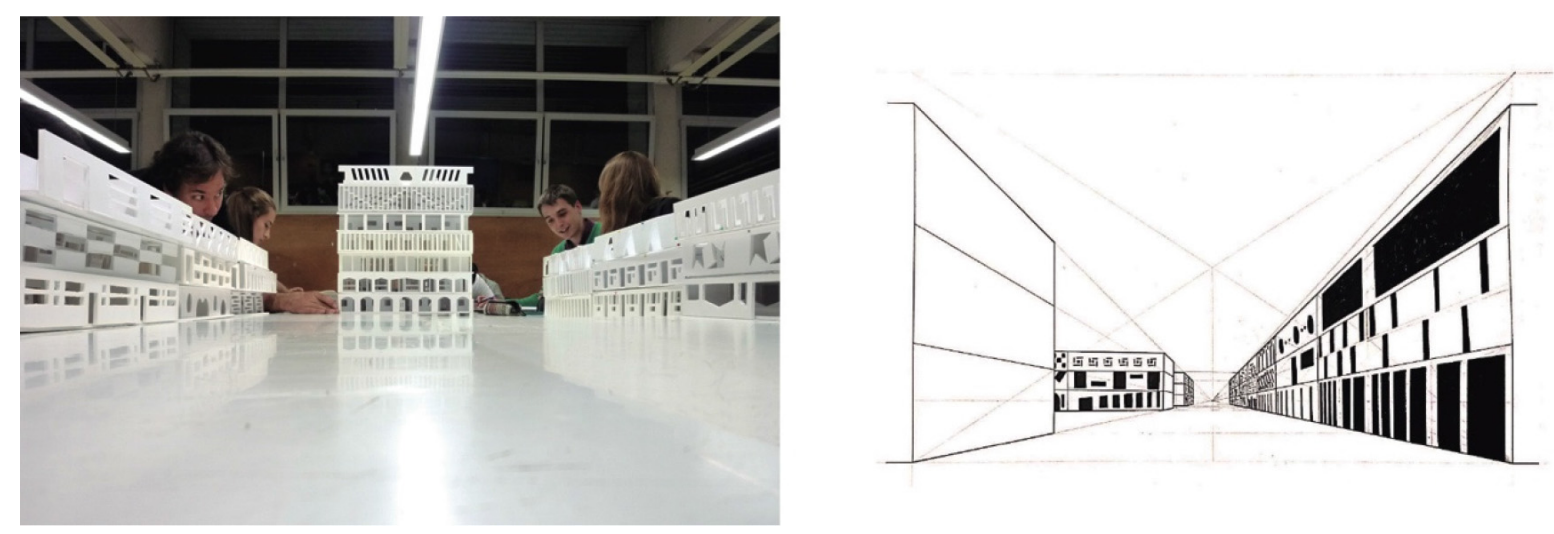

Figure 11. Photograph of the group model from exercise 7 and its drawing in perspective

(the authors and student E. Romeu, 2016)

\subsection{Transform}

In the Transform stage, full attention is given to the basic parameters that define the habitability of an interior space in a home. The lecture on Forms and habitability shows, through different examples that have been chosen, the capacity that forms have to create interior architectural spaces with great quality and complexity based on basic strategies of space transformation. Operations like segregating, unbalancing, concentrating, unfolding or retracting are some of the many mechanisms used to adapt an interior space that must include both set architectural elements, such as basic furnishings, to achieve a qualitatively high level of habitability.

The final exercise is carried out in three correlative phases. The student is faced for the first time with the comprehensive resolution of a living space, in which he/she puts into practice the knowledge and skills acquired during the first two parts of the course.

The first phase consists of designing and constructing at least a floor slab and a staircase inside a space measuring $5.8 \times 5.8 \times 3.6 \mathrm{~m}$, to create a living space in which to live, study and eat. The results obtained 
illustrate different ways of occupying interior space using one, two or more horizontal platforms that, in some cases, become furnishings, integrating structural elements and vertical communication.
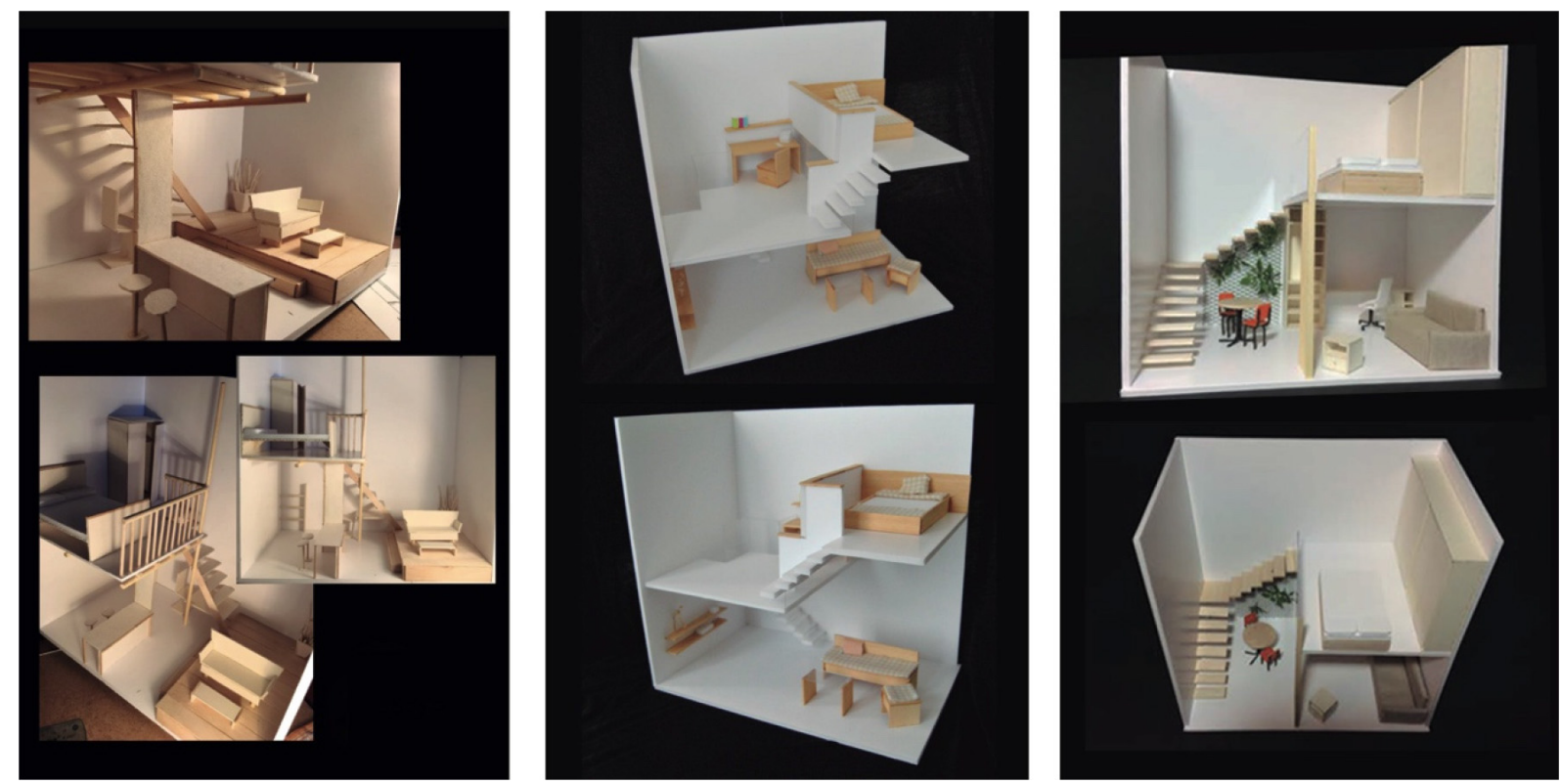

Figure 12. Photographs of the models from exercise 8 (students E. Romeu, C. Ibáñez and I. Bigas, 2016)

In the second phase, the student must resolve the façades and roof based on the proposed interior spaces, using the lattice as part of the project and designing a skylight in the roof. For the final delivery, students finish developing the project and complement the interior part of the space, defining its materiality and designing the furnishings. The assignment is submitted in the form of a model built to $1 / 20$ scale and with the dimensional drawings showing the floor plan, elevation and sections.
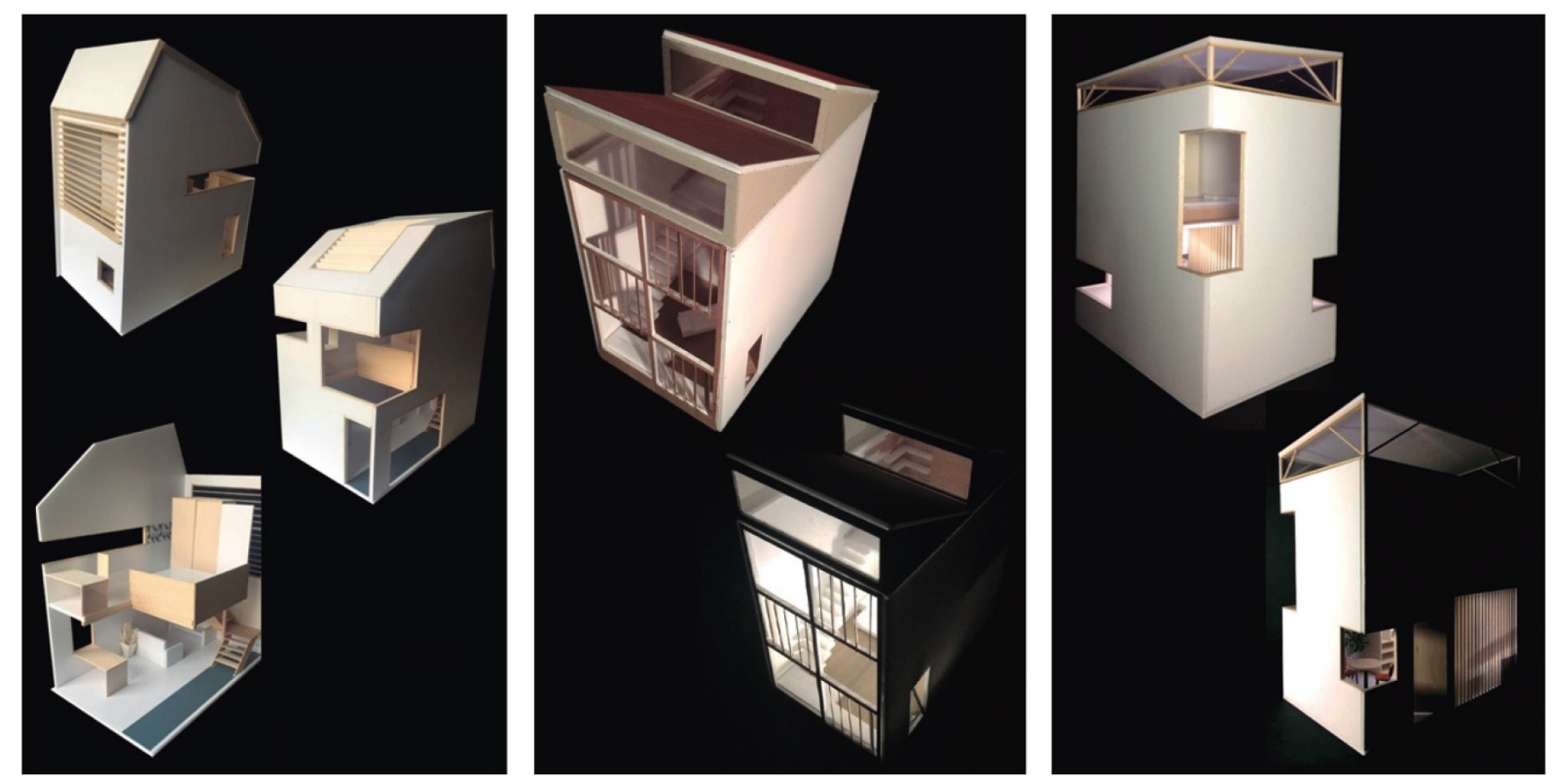

Figure 13. Photographs of models from exercises 9 and 10 (students E. Romeu, R. Nogué and I. Bigas, 2016)

In this case, there is also a wide variety of results in the students' proposals that exemplify the different ways of resolving the volumes, façades, roofs and openings to let light in, complementing and qualifying the design of the interior space from the previous exercise. 

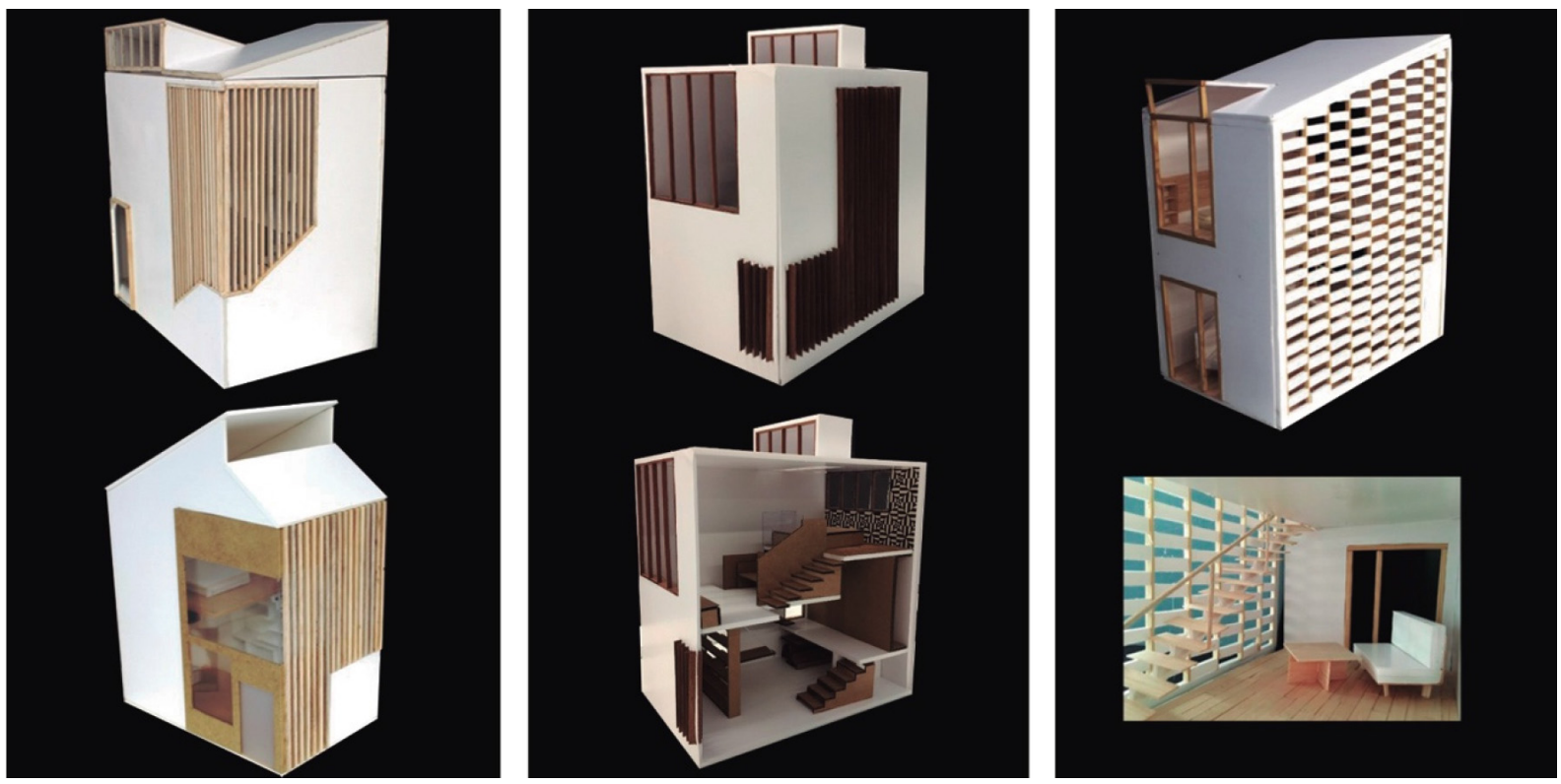

Figure 14. Photographs of models from exercises 9 and 10 (students H. Armengol, S. Gas and P. Cladera, 2016)

\section{Conclusions}

Based on the experience of two consecutive years applying this teaching program (in the 2015-16 and 2016-17 academic years), we can state that based on certain pre-established methodological bases and the contents presented in the lectures, put into practice and discussed in the design studio, the students acquire the capacity to apply and experiment with the concepts learned, while at the same time strengthening their capacity for reflection, abstraction and creation. By analyzing, drawing, building, transforming, deforming and reforming forms and systems, we see the usefulness of the formal language and its infinite potential to solve any design problem, regardless of whether it is on a large or small scale.

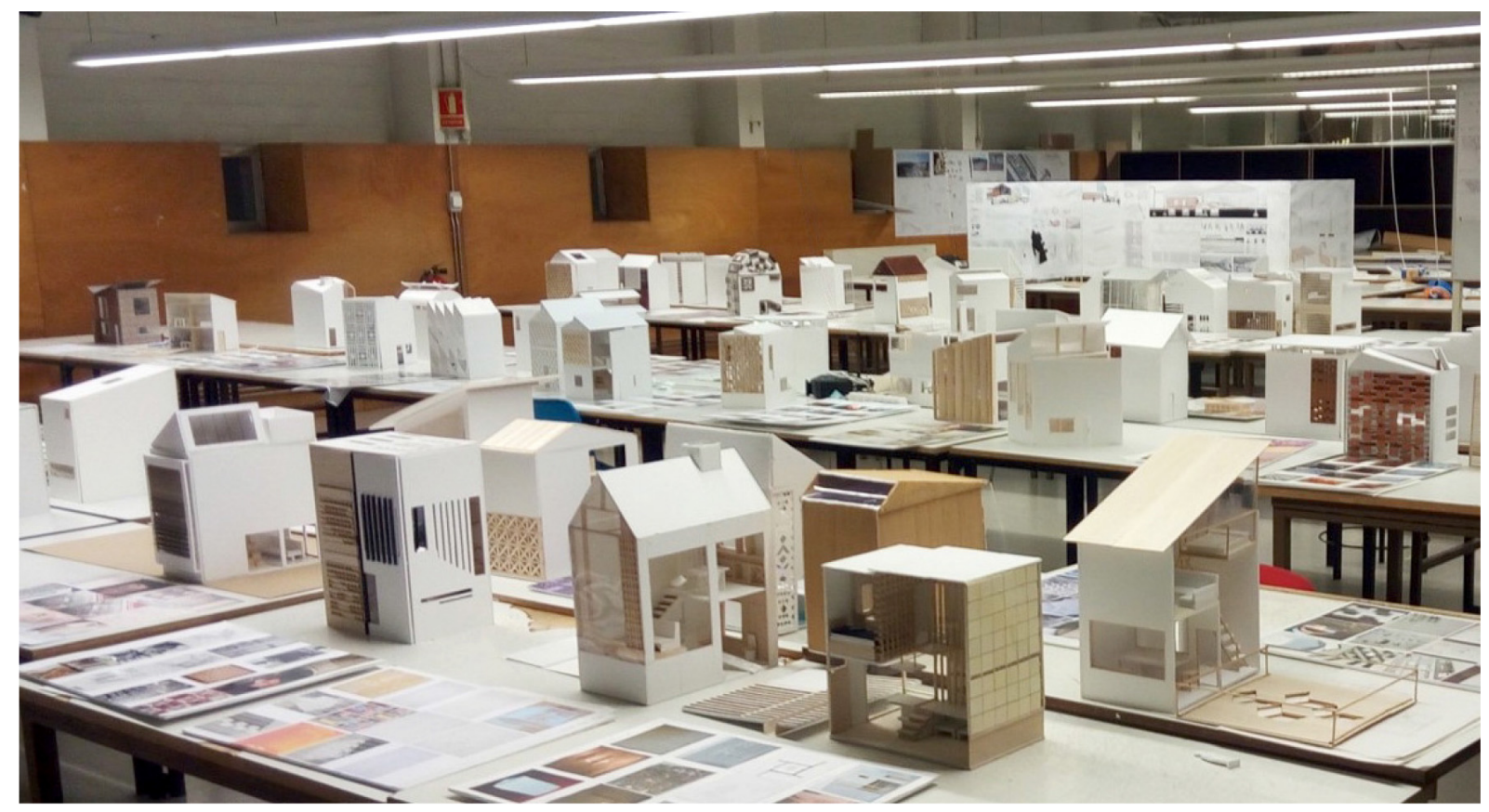

Figure 15. Photographs of the final submission (2016)

Each week very different objects are designed and built to meet different functional, compositional and material needs of the architectural project. The limitation and specific dimensioning of the approach to each exercise permits focusing on and strengthening the students' work, without getting bogged down by 
secondary matters or in excessively complex approaches that would divert us from the main objective. Through progressive learning, students acquire knowledge and practice that are valuable for the evolution of their career path.

The quality of the results in this teaching experience have shown us that instruction on the language of forms is fundamental and constitutes a solid base to take on the full practice of the architectural design in the future.

\section{Declaration of Conflicting Interests}

The authors declared no potential conflicts of interest with respect to the research, authorship, and/or publication of this article.

\section{Funding}

The authors received no financial support for the research, authorship, and/or publication of this article.

\section{References}

Aicher, O. (2001). Analógico y digital (129-161). Barcelona: Gustavo Gili.

Argan, G.C. (1951/1983). Walter Gropius y la Baubaus (23-66). Turín: Einaudi. Barcelona: Gustavo Gili.

Cook, T. (1914). The Curves of Life. London: Constable and Company.

Dezzi-Bardeschi, M. (1977). Frank Lloyd Wright. Florencia: Sansoni.

Droste, M. (1993). Baubaus 1919-1933. Berlin: Benedikt Taschen.

Kahn, L.I. (1960). Structure and Form. Voice of America Forum Lectures. Architecture Series, no. 6. Transcribed broadeast from Washington, D.C., November 21. Reprinted latter as Form and Design.

Kahn, L.I. (1962). Premisa. In Notebooks and Drawings of L. Kabn. Philadelphia, New York: Falcon Press.

Kahn, L.I. (1969). An Interview, Via Magazine. Philadelphia, Pennsylvania, 11 January 69. In Wurman, R.S. (Ed.), 52.

Khan-Magomedov, S.O. (1990). Vhutemas: Moscou 1920-1930. Paris: Éditions du Regard.

Kolb, D.A., \& Fry, R. (1975). Toward an applied theory of experiential learning. In Cooper, C. (Ed.). Theories of Group Process. London: John Wiley.

Krampen, M., \& Hörmann, G. (2003). Die Hochschule für Gestaltung Ulm: Anfänge eines Projektes der unnachgiebigen Moderne. The Ulm School of Design - Beginnings of a Project of Unyielding Modernity. Berlin: Ernst \& Sohn.

Le Corbusier (1923). Vers une Architecture. Paris: Crès.

Loos, A. (1898/1993). Adolf Loos. Escritos I, 1897-1909. Madrid: El Croquis.

Munari, B. (1968). El arte como oficio. Barcelona: Labor, 28-30; 93-96.

Ozentfant, A., \& Jeanneret, Ch.E. (1921). Las ideas del espíritu nuevo en los libros y en la prensa. L’Esprit Noveau, 11-12.

Sennett, R. (2009). El artesano. Barcelona: Anagrama.

Tatarkiewicz, W. (1975/2002). Historia de seis ideas. Madrid: Tecnos, 253-278. 
Thomson, D. (1917). On Growth and Form. Cambridge: The Presss Syndicate of the University of Cambridge.

Zevi, B. (1960). Architettura in nuce. Milano: Istituto per la Collaborazione Cuturale.

Published by OmniaScience (www.omniascience.com)

Journal of Technology and Science Education, 2018 (www.jotse.org)

(c) (1) (8)

Article's contents are provided on an Attribution-Non Commercial 4.0 Creative commons International License.

Readers are allowed to copy, distribute and communicate article's contents, provided the author's and JOTSE

journal's names are included. It must not be used for commercial purposes. To see the complete licence contents, please visit https://creativecommons.org/licenses/by-nc/4.0/. 